\title{
A MODIFIED ANALYTICAL HIERARCHY PROCESS DESIGN EVALUATION METHODS FOR PRODUCT RECOVERY
}

${ }^{1}$ Go, T.F.* ${ }^{2}$ Wahab, D.A., ${ }^{3}$ Hishamuddin, H., ${ }^{4}$ Yap, W.S., ${ }^{5}$ Sockalingam, K.

${ }^{1}$ Centre for Advance Materials and Intelligent Manufacturing, Faculty of Engineering, Built Environment \& Information Technology, SEGi University, 47810 Petaling Jaya, Selangor, Malaysia.

${ }^{2}$ Centre for Automotive Research, Faculty of Engineering and Built Environment, Universiti Kebangsaan Malaysia, 43600, Malaysia.

${ }^{3}$ Department of Mechanical \& Manufacturing, Faculty of Engineering and Built Environment, Universiti Kebangsaan Malaysia, 43600 Bangi, Selangor, Malaysia.

.${ }^{4}$ Perunding PAC, Lorong Sentul Kecil, Sentul, 51100 Kuala Lumpur, Malaysia.

${ }^{5}$ Department of Mechanical Engineering, Faculty of Engineering, Built Environment \& Information Technology, SEGi University, 47810 Petaling Jaya, Selangor, Malaysia.

* Corresponding Author: gotzefong@ @egi.edu.my TEL: (+603)- 61451777

\begin{abstract}
The absence of existing standards for product recovery planning and the associated difficulty in prioritising the conflicting design requirements are among the main challenges faced during product design. In this paper, a concept for the Design for Multiple Life-Cycles (DFMLC) is proposed to address this situation. The objective of the DFMLC model is to assist designers in evaluating design attributes of Multiple Life-Cycle Products (MLCP) at the early design stage. The methodology adopted for the evaluation of MLCP design strategies has been based on a modified Analytical Hierarchy Process (AHP). Two mapping matrices of the design guidelines and design strategies concerning MLCP design attributes were developed for the modified AHP model. Disassemblability (> $21 \%$ ) was found to be the most important design element for MLCP followed by serviceability (> $20 \%$ ) and reassembly (>12\%).
\end{abstract}

Keywords: Product recovery; Design evaluation; AHP; Disassemblability.

\section{Introduction}

The implementation of the Malaysia Automotive Remanufacturing Roadmap 2014 showed the level of awareness and understanding of the concepts associated with remanufacturing within 
the automotive industry be enhanced (Mai, 2014). Moreover, one of the targets of Malaysia National Automotive Policy 2020 is RM10 billion worth of exports of remanufactured parts and component to be achieved by 2030 (Miti, 2020). The launching of the roadmap indicated that Malaysia had started to promote remanufacturing with local automotive manufacturers thereby directly contributing to the circular economy. Circular economy could be supported by product sustainability. Product sustainability has many advantages, although applying the concept is quite challenging and requires changes to conventional methods of manufacturing and in producing products. Therefore, the circular material flows have been investigated within the automotive industry (Kurilova-Palisaitiene et al, 2015) including remanufacturing.

The concern of circular material flows leads to the concept and trend to design sustainable products are ultimately never discarded. Delivering sustainable products requires deliberate actions from all parties that are engaged in developing products from the design stage right through to the product's end-of-life. Design for Multiple Life-Cycles (DFMLC) creates a portfolio of design guidelines which could lead to product proliferation via the utilisation of multiple materials supported by recovery options. In this paper emphases implementation of DFMLC during product design phase for re-manufacturable products. In design evaluation involving multiple attributes, the appropriate methods of evaluation and selection need to be identified.

When assessing DFMLC, several criteria or factors can assist to predict whether a product will constitute Multiple Life-Cycles. Hence, the design evaluation for designing Multiple LifeCycles Product (MLCP) requires a multi-criteria decision making (MCDM) tool during the conceptual design stage. The literature on design alternative evaluation and selection can be classified into five distinct categories (Zha et al, 2004): multi-criteria utility analysis, fuzzy set analysis, designing analytic methodology, the hybrid approach and the information content approach. Table 1 presents a summary of design evaluation methods based on the MCDM method. 
Table 1. Summary of design evaluation methods

\begin{tabular}{|c|c|c|c|c|}
\hline No. & MCDM approach & The purpose of the design evaluation & Reference(s) & Justification for DFMLC \\
\hline \multirow[b]{2}{*}{1} & \multirow{2}{*}{$\begin{array}{l}\text { QFD (Quality } \\
\text { Function } \\
\text { Deployment) }\end{array}$} & To design a manufacturable engine & Yuksel, 2010 & \multirow{2}{*}{$\begin{array}{l}\text { This method is appropriate to achieve customer } \\
\text { satisfaction but cannot ensure that the product } \\
\text { specification meets the criteria of life-cycle } \\
\text { requirements. }\end{array}$} \\
\hline & & To develop a customer satisfaction model. & $\begin{array}{l}\text { Nahm et al, } \\
2013\end{array}$ & \\
\hline 2 & Pugh Matrix & $\begin{array}{l}\text { To evaluated design selection of a hydrostatic } \\
\text { bearing pad for an automotive application. }\end{array}$ & $\begin{array}{l}\text { Seperamaniam } \\
\text { et al,2017 }\end{array}$ & $\begin{array}{l}\text { This method is not a quantitative approach and } \\
\text { requires a good datum as a guide for designing an } \\
\text { MLCP. }\end{array}$ \\
\hline \multirow[b]{2}{*}{3} & \multirow{2}{*}{$\begin{array}{l}\text { Fuzzy hybrid } \\
\text { TOPSIS (Technique } \\
\text { for order preference } \\
\text { by similarity to ideal } \\
\text { solution) }\end{array}$} & $\begin{array}{l}\text { To determine the decision strategies for best } \\
\text { alternative selection for reprocessing }\end{array}$ & $\begin{array}{l}\text { Wadhwa et al, } \\
\text { (2009) }\end{array}$ & \multirow{2}{*}{$\begin{array}{l}\text { This method requires a good datum as an ideal } \\
\text { solution for designing MLCP. However, there is no } \\
\text { perfect solution for all types of products. }\end{array}$} \\
\hline & & $\begin{array}{l}\text { To determine the risk priorities of the failure } \\
\text { modes identified in the failure mode and effects } \\
\text { analysis. }\end{array}$ & Liu et al,2015 & \\
\hline \multirow[t]{2}{*}{4} & \multirow[t]{2}{*}{ AHP } & $\begin{array}{l}\text { To incorporate the design criteria into a } \\
\text { comprehensive information system for supporting } \\
\text { Design for Remanufacturing activities. }\end{array}$ & $\begin{array}{l}\text { Abdullah et al, } \\
2013\end{array}$ & \multirow{2}{*}{$\begin{array}{l}\text { This MCDM method can be used in design } \\
\text { evaluation for MLC requirements which involve } \\
\text { more than one criterion. However, inconsistency in } \\
\text { the views of decision makers is one of the setbacks } \\
\text { of the method. }\end{array}$} \\
\hline & & To evaluate sustainable manufacturing practices. & $\begin{array}{l}\text { Gupta et al, } \\
2015\end{array}$ & \\
\hline \multirow{2}{*}{5} & \multirow{2}{*}{ Fuzzy-AHP } & $\begin{array}{l}\text { To prioritise customer requirements in product } \\
\text { design. }\end{array}$ & $\begin{array}{l}\text { Mastura et al, } \\
2015\end{array}$ & \multirow{2}{*}{$\begin{array}{l}\text { This hybrid model is widely applied to solve the } \\
\text { inconsistency problem in the conventional AHP } \\
\text { model. }\end{array}$} \\
\hline & & $\begin{array}{l}\text { To evaluate the upgradability of a brake calliper } \\
\text { in the design. }\end{array}$ & Aziz et al, 2017 & \\
\hline 6 & PR-MCDT & To design a remanufacturable product. & $\begin{array}{l}\text { Alamerew \& } \\
\text { Brissaud, } 2017\end{array}$ & $\begin{array}{l}\text { This method considered the impact of EOL } \\
\text { strategies on the environment and economy but did } \\
\text { not evaluate the design of product configuration } \\
\text { that might facilitate the product recovery process. }\end{array}$ \\
\hline \multirow{2}{*}{7} & \multirow{2}{*}{$\begin{array}{l}\text { CDTC (conceptual } \\
\text { design to cost) }\end{array}$} & $\begin{array}{l}\text { To generate cost-effective assembly sequence for } \\
\text { complex products. }\end{array}$ & Favi et al, 2016 & \multirow{2}{*}{$\begin{array}{l}\text { The effective cost and performance to achieve an } \\
\text { extended service period with good quality are } \\
\text { difficult to obtain the trade-off balance point. }\end{array}$} \\
\hline & & $\begin{array}{l}\text { To predict product EOL costs at the early design } \\
\text { concept. }\end{array}$ & $\begin{array}{l}\text { Cheung et al, } \\
2015\end{array}$ & \\
\hline
\end{tabular}


The existing product recovery decision methods either focus on technical, economic or social aspects such as the Product Recovery Multi-Criteria Decision Tool (PR-MCDT) by Alamerew and Brissaud (2017). Alternatively, Priyono et al (2015) only focused on a single product criterion such as the strategic operations framework for disassembly which focused on disassembly in remanufacturing. Moreover, there is a lack of an acceptable approach that adopts a methodology for analysing multiple design criteria such as simplicity, disassemblability, modularity and others simultaneously. Moreover, it can be observed from Table 1 that there is no discussion on the weight distribution among the factors considered in DFMLC. Therefore, a model of the DFMLC is proposed in this paper as a sustainable product development strategy. Furthermore, a modified AHP model be proposed as the design evaluation method which guides the structural design, material usage, assembly and disassembly methods for recovery purpose. DFMLC is an approach that minimises material usage and reprocessing time and prolongs the life of the product(s). Therefore, MLCP can significantly contribute towards reducing material usage, wastage and land degradation.

The remaining of the paper is organized as follows: Section 2 outlines the materials and methods which the AHP hierarchy structure of DFMLC and Pairwise Comparison Matrices for modified AHP. Section 3 presents results and discussion with a case study. Finally, section 4 concludes the findings of this paper.

\section{Materials and Methods}

DFMLC is a design approach that allows a product and its components to enter a series of service lives after undergoing appropriate EOL treatment such as reuse, remanufacturing and recycling at the end of each life-cycle. In this paper, a weightage determinant method for MLCP design elements was developed based on AHP. A modified AHP model of the product design matrices for the MLCP based on the proposed design elements and the evaluation function will be developed. The evaluation function reflects the designer's preferences for sets of multiple design elements in a weightage format. The proposed model provides a quantitative basis for modifying a design to increase its utility to the decision-maker.

\subsection{The AHP Hierarchy Structure of DFMLC}

The hierarchy structure of the AHP for DFMLC in this paper comprising four levels is shown in Figure 1. Level 1 presents the main goal of the product design which is DFMLC. Level 2 
presents the design criteria which includes the Product Structure Guidelines (PSG), Material Selection Guidelines (MSG), Labelling and Finishing Guidelines (LFG) and Fastening Guidelines (FG). Level 3 presents the DFXs with DFX 1, DFX 2 and DFX 3 which represent the Design for EOL Option, Design for Configuration and Design for Life-Cycle extension respectively. Finally, level 4 presents eight proposed design elements. Once the AHP model is set up, the priorities need to be developed, and weights are then assigned to each level.

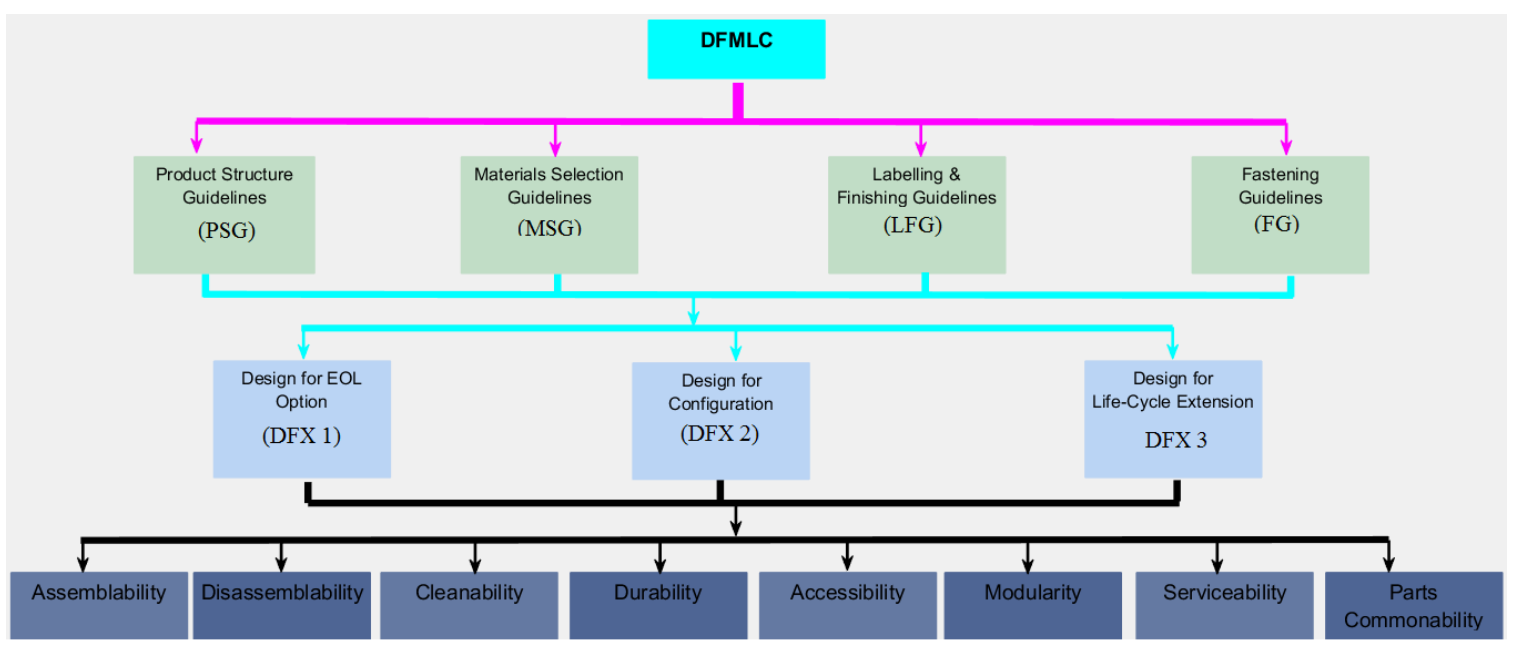

Figure 1. The AHP hierarchy structure of DFMLC.

\subsection{Pairwise Comparison Matrices in Modified AHP}

A method of estimating a pairwise comparison relative importance scalar for AHP has been proposed in this paper. Figure 2 presents the flowchart for the modified AHP. This modified AHP consists of 10 steps, beginning with defining the design problem, generating design ideas, analysing the ideas via mapping with design attributes in 3 levels and developing the relevant pairwise comparison matrices, then checking the matrices consistency before generating an important ranking for each design element.

A new method of estimating the relative importance scale in pairwise comparison matrices for AHP has been developed in this paper. The mapping matrices of the design guidelines and design strategies concerning the proposed design elements were developed for the modified AHP model as shown in Table 2, Table 4 and Table 5. The detail of the design guidelines can refer to the Go et al (2015). Design strategies be generated from the designer's idea after referred the design guideline to design a sustainable product. A set of modified relative importance scales were generated based on the two mapping matrices for assessing pairwise comparison. Thus, the modified AHP introduced a simple and effective method for evaluating 
the importance scale for MLCP design attributes to generate the pairwise comparison matrix.

Table 2 presents the mapping design guidelines concerning design criteria with " 1 " indicating the design guideline that affects the design criteria; else " 0 " indicating that the design guideline does not affect the design criteria. Table 4 and Table 5 present the mapping design strategies with the proposed design criteria. From Table 4, there are 28 design strategies be generated for designing a re-manufacturable automotive engine. After the mapping done, then the ratio of the number of design strategies effect on the two compared design attribute can be calculated.

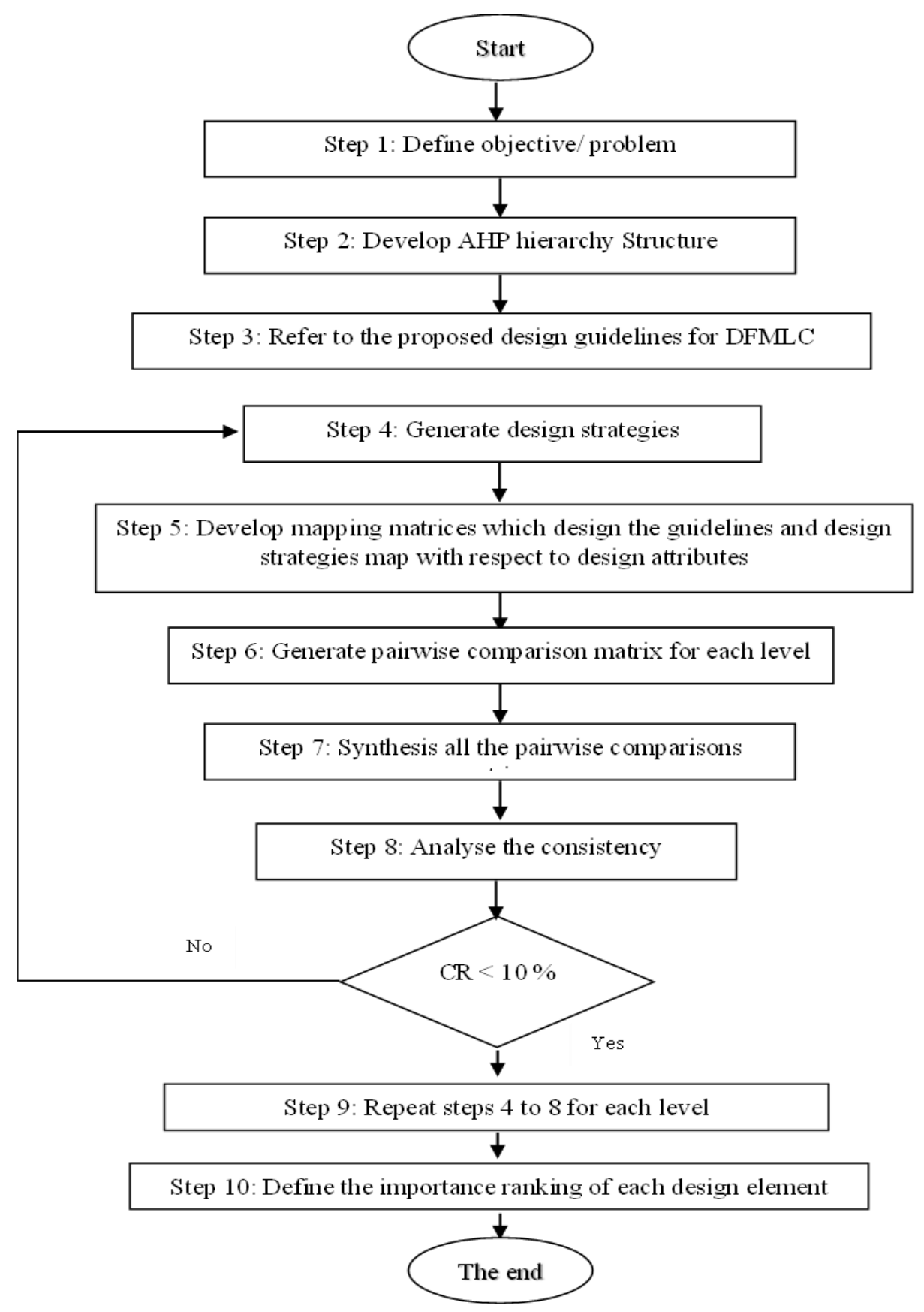

Figure 2. Flowchart of the modified AHP 
Table 2. Example of mapping matrix design guidelines against the design criteria.

\begin{tabular}{|l|c|c|c|c|}
\hline \multicolumn{1}{|c|}{ Design guidelines } & PSG & MSG & LFG & FG \\
\hline $\begin{array}{l}\text { Provide product performance of the failure mode } \\
\text { and effect analysis to identify and eliminate critical } \\
\text { failure modes. }\end{array}$ & 1 & 1 & 0 & 0 \\
\hline $\begin{array}{l}\text { Provide a clear indication of reusable or re- } \\
\text { manufacturable components within the product. }\end{array}$ & 0 & 0 & 1 & 0 \\
\hline Increase upgradability of components. & 1 & 1 & 0 & 0 \\
\hline Increase modularity of components. & 1 & 0 & 0 & 0 \\
\hline Reduce the variety of parts. & 1 & 1 & 0 & 1 \\
\hline Reduce the disassembly time. & 1 & 1 & 0 & 0 \\
\hline Avoid the use of toxic materials. & & 0 & 0 \\
\hline
\end{tabular}

The recommended equations for determining the importance scale for pairwise comparison in this paper are given below.

The considerations in pairwise comparison of design criteria in Level 2 of the AHP hierarchy structure of DFMLC is defined as per Equation 1.

$$
\text { DFMLC }=x_{1} \times x_{2} \times 100 \%
$$

Where;

$x_{1}=\quad$ Ratio of the number of design guidelines effect on the two compared design criteria.

$x_{2}=$ Ratio of the number of design strategies effect on the two compared design criteria.

The considerations in pairwise comparison of DFXs in Level 3 of the AHP hierarchy structure of DFMLC is defined as per Equation 2.

$$
\text { DFMLC }=y_{1} \times y_{2} \times 100 \%
$$

Where;

$y_{1}=$ Ratio of the number of design guidelines effect on the two compared DFXs.

$y_{2}=\quad$ Ratio of the number of design strategies effect on the two compared DFXs.

The considerations in pairwise comparison of design elements in Level 4 of the AHP hierarchy structure of DFMLC is defined as per Equation 3.

$$
\text { DMFLC }=z_{1} \times z_{2} \times 100 \%
$$


Where;

$z_{1}=$ Ratio of the number of design guidelines effect on the two compared design elements.

$z_{2}=$ Ratio of the number of design strategies effect on the two compared design elements.

After the total ratio is determined in a percentage form, the relative importance scale in pairwise comparison matrices for AHP can next be determined by referring to Table 3. The table shows a modified scale for the relative importance scale for pairwise comparison to develop a pairwise comparison matrix for AHP.

Table 3. The modified scale for the relative importance in pairwise comparison.

\begin{tabular}{|l|l|l|}
\hline Score & Scale & The relative important \\
\hline$<15 \%$ & 1 & Equally important \\
\hline $15-25 \%$ & 2 & Intermedia values \\
\hline $25-35 \%$ & 3 & Moderately important \\
\hline $35-45 \%$ & 4 & Intermedia values \\
\hline $45-55 \%$ & 5 & Strongly important \\
\hline $55-65 \%$ & 6 & Intermedia values \\
\hline $65-75 \%$ & 7 & Very strongly important \\
\hline $75-85 \%$ & 8 & Intermedia values \\
\hline$>85 \%$ & 9 & Extremely important \\
\hline
\end{tabular}

In the product design evaluation process, this modified AHP may assist in clarifying the design ideas and strategies for designing a reusable or re-manufacturable product. The hierarchical method can also be applied for calculating the weighing measures of design elements for different products that were previously designed consisting of MLC. The modified AHP is applied with its extension to create weights for quantitative and product designer opinions. These weights, in turn, are used to prioritise the level of importance of the design elements. Hence, the method with the aid of a numerical example is presented.

\section{Results \& Discussion}

In-depth interviews were conducted with a remanufacturer to identify the design elements for MLCP and to obtain design proposals for an appropriate re-manufacturable automotive engine. Based on the interviews, 28 design strategies for automotive components have been proposed and discussed to improve the capability of MLC as shown in Table 4 and Table 5. The mapping 
matrix of the design strategies concerning the proposed design attributes of the modified AHP model is shown in Table 4 and Table 5. All pairwise comparison matrices for each of the AHP levels have been constructed using Equations (1), (2) and (3) and by referring to Table 3. Subsequently, the priority vector of MLCP attributes was determined from all pairwise comparison matrices. Therefore, the weightage of MLCP design attributes has been determined using the proposed modified AHP.

Table 4. Mapping of design strategies for re-manufacturable automotive engine to the design elements in Level 2 and Level 3 of the AHP hierarchy structure of DFMLC

\begin{tabular}{|c|c|c|c|c|c|c|c|c|}
\hline No & Attributes MLCP & $\underbrace{2}_{\mathscr{L}}$ & 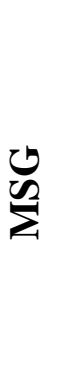 & 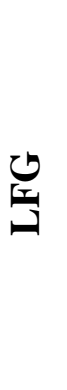 & $\bigcup_{1}$ & $\underset{x}{\bar{x}}$ & $\underset{x}{x}$ & 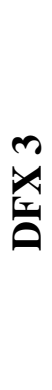 \\
\hline DS 1 & $\begin{array}{l}\text { Provide clear distinctive features that allow } \\
\text { for easy recognition. }\end{array}$ & 1 & 0 & 1 & 0 & 1 & 0 & 0 \\
\hline DS 2 & $\begin{array}{l}\text { Provide orienting features on non-symmetries } \\
\text { for easy handling. }\end{array}$ & 1 & 0 & 0 & 0 & 1 & 1 & 0 \\
\hline DS 3 & Provide alignment features. & 1 & 0 & 0 & 0 & 1 & 1 & 1 \\
\hline DS 4 & $\begin{array}{l}\text { Provide the specification of product } \\
\text { parameters and tolerances that are within the } \\
\text { natural capabilities of the manufacturing } \\
\text { process (process capability index Cp and } \\
\text { Cpk). }\end{array}$ & 1 & 0 & 1 & 1 & 1 & 1 & 0 \\
\hline DS 5 & Provide clear installation manuals. & 0 & 0 & 1 & 0 & 1 & 0 & 1 \\
\hline DS 6 & $\begin{array}{l}\text { Provide clear maintenance and repair } \\
\text { manuals, including the opening method for } \\
\text { cleaning and repairing. }\end{array}$ & 0 & 0 & 1 & 0 & 1 & 1 & 1 \\
\hline DS 7 & $\begin{array}{l}\text { Provide color-coding lubricating points on the } \\
\text { parts that must be cleaned or maintained. }\end{array}$ & 1 & 0 & 1 & 0 & 0 & 1 & 1 \\
\hline DS 8 & $\begin{array}{l}\text { Provide proper spacing that ensures the use of } \\
\text { fastening tools. }\end{array}$ & 1 & 1 & 0 & 0 & 1 & 1 & 0 \\
\hline DS 9 & $\begin{array}{l}\text { Provide mathematical confirmation of } \\
\text { mechanical design choices, such as stress and } \\
\text { strength design. }\end{array}$ & 1 & 1 & 0 & 0 & 0 & 1 & 1 \\
\hline DS 10 & Increase commonality of components. & 1 & 1 & 0 & 0 & 1 & 1 & 1 \\
\hline DS 11 & $\begin{array}{l}\text { Increase reliability and durability of the } \\
\text { product by selecting suitable materials. }\end{array}$ & 0 & 1 & 0 & 0 & 1 & 1 & 0 \\
\hline DS 12 & Increase simplicity in product design. & 1 & 1 & 1 & 1 & 1 & 1 & 0 \\
\hline DS 13 & $\begin{array}{l}\text { Increase corrosion and dirt resistance of } \\
\text { fasteners. }\end{array}$ & 0 & 1 & 0 & 1 & 1 & 1 & 1 \\
\hline
\end{tabular}




\begin{tabular}{|c|c|c|c|c|c|c|c|c|}
\hline No & Attributes MLCP & $\bigcup_{\mathscr{L}}$ & $\underset{\mathscr{E}}{\mathscr{\mathscr { L }}}$ & $\underset{\Xi}{0}$ & $\bigcup_{1}$ & $\underset{x}{x}$ & $\underset{n}{n}$ & $\stackrel{n}{a}$ \\
\hline DS 14 & Increase corrosion and dirt resistance of parts. & 1 & 1 & 0 & 0 & 1 & 1 & 1 \\
\hline DS 15 & $\begin{array}{l}\text { Increase corrosion and dirt resistance of } \\
\text { surfaces. }\end{array}$ & 1 & 1 & 1 & 0 & 1 & 1 & 0 \\
\hline DS 16 & Increase modular design. & 1 & 0 & 0 & 0 & 1 & 1 & 1 \\
\hline DS 17 & $\begin{array}{l}\text { Increase standardisation and use of common } \\
\text { parts and materials. }\end{array}$ & 1 & 1 & 0 & 0 & 1 & 1 & 0 \\
\hline DS 18 & $\begin{array}{l}\text { Increase standardisation and use of common } \\
\text { fasteners. }\end{array}$ & 1 & 0 & 0 & 1 & 0 & 1 & 1 \\
\hline DS 19 & $\begin{array}{l}\text { Increase standardisation and use of common } \\
\text { connections. }\end{array}$ & 1 & 0 & 0 & 0 & 1 & 0 & 1 \\
\hline DS 20 & $\begin{array}{l}\text { Increase the usage of proven parts, materials } \\
\text { and preferred design. }\end{array}$ & 1 & 1 & 0 & 0 & 1 & 1 & 0 \\
\hline DS 21 & $\begin{array}{l}\text { Reduce part count by incorporating multiple } \\
\text { functions into single parts. }\end{array}$ & 0 & 1 & 0 & 0 & 1 & 0 & 0 \\
\hline DS 22 & Reduce disassembly time. & 1 & 1 & 0 & 1 & 0 & 1 & 1 \\
\hline DS 23 & Reduce assembly steps. & 1 & 0 & 0 & 0 & 1 & 1 & 1 \\
\hline DS 24 & $\begin{array}{l}\text { Reduce geometric features that trap } \\
\text { contaminants over the service life. }\end{array}$ & 1 & 0 & 1 & 0 & 1 & 1 & 0 \\
\hline DS 25 & $\begin{array}{l}\text { Reduce the number of cavities that are } \\
\text { capable of collecting residue during cleaning } \\
\text { operations. }\end{array}$ & 0 & 0 & 1 & 0 & 1 & 0 & 1 \\
\hline DS 26 & $\begin{array}{l}\text { Avoid the use of regulated and restricted } \\
\text { materials. }\end{array}$ & 1 & 1 & 0 & 0 & 1 & 1 & 0 \\
\hline DS 27 & $\begin{array}{l}\text { Avoid product or part features that can be } \\
\text { damaged during disassembly processes. }\end{array}$ & 1 & 0 & 0 & 1 & 1 & 1 & 0 \\
\hline DS 28 & $\begin{array}{l}\text { Avoid product or part features that can be } \\
\text { damaged during cleaning processes. }\end{array}$ & 1 & 0 & 1 & 0 & 1 & 0 & 0 \\
\hline
\end{tabular}


Table 5. Mapping of design strategies for re-manufacturable automotive engine to the design elements in Level 4 of the AHP hierarchy structure of DFMLC

\begin{tabular}{|c|c|c|c|c|c|c|c|c|c|}
\hline No & Attributes MLCP & 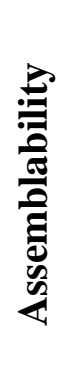 & 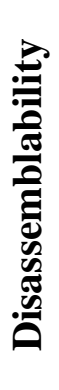 & 莺 & 尝 & 莬 & 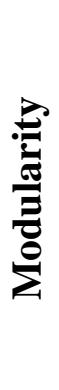 & : & 己̇ \\
\hline DS 1 & $\begin{array}{l}\text { Provide clear distinctive features } \\
\text { that allow for easy recognition. }\end{array}$ & 0 & 0 & 1 & 0 & 1 & 0 & 1 & 0 \\
\hline DS 2 & $\begin{array}{l}\text { Provide orienting features on non- } \\
\text { symmetries for easy handling. }\end{array}$ & 1 & 1 & 0 & 0 & 1 & 1 & 1 & 0 \\
\hline DS 3 & Provide alignment features. & 1 & 1 & 0 & 0 & 0 & 1 & 1 & 0 \\
\hline DS 4 & $\begin{array}{l}\text { Provide the specification of product } \\
\text { parameters and tolerances that are } \\
\text { within the natural capabilities of the } \\
\text { manufacturing process (process } \\
\text { capability index Cp and Cpk). }\end{array}$ & 1 & 0 & 0 & 1 & 0 & 1 & 1 & 0 \\
\hline DS 5 & Provide clear installation manuals. & 0 & 0 & 0 & 0 & 0 & 0 & 0 & 0 \\
\hline DS 6 & $\begin{array}{l}\text { Provide clear maintenance and } \\
\text { repair manuals, including the } \\
\text { opening method for cleaning and } \\
\text { repairing. }\end{array}$ & 1 & 0 & 0 & 0 & 0 & 0 & 1 & 0 \\
\hline DS 7 & $\begin{array}{l}\text { Provide color-coding lubricating } \\
\text { points on the parts that must be } \\
\text { cleaned or maintained. }\end{array}$ & 0 & 0 & 1 & 1 & 1 & 0 & 1 & 0 \\
\hline DS 8 & $\begin{array}{l}\text { Provide proper spacing that ensures } \\
\text { the use of fastening tools. }\end{array}$ & 0 & 0 & 0 & 1 & 0 & 0 & 0 & 0 \\
\hline DS 9 & $\begin{array}{l}\text { Provide mathematical confirmation } \\
\text { of mechanical design choices, such } \\
\text { as stress and strength design. }\end{array}$ & 0 & 0 & 0 & 1 & 0 & 0 & 0 & 0 \\
\hline DS 10 & $\begin{array}{l}\text { Increase commonality of } \\
\text { components. }\end{array}$ & 1 & 1 & 1 & 0 & 0 & 0 & 1 & 1 \\
\hline DS 11 & $\begin{array}{l}\text { Increase reliability and durability of } \\
\text { the product by selecting suitable } \\
\text { materials. }\end{array}$ & 0 & 0 & 1 & 1 & 0 & 0 & 1 & 0 \\
\hline DS 12 & $\begin{array}{l}\text { Increase simplicity in product } \\
\text { design. }\end{array}$ & 1 & 1 & 0 & 0 & 0 & 0 & 1 & 1 \\
\hline DS 13 & $\begin{array}{l}\text { Increase corrosion and dirt } \\
\text { resistance of fasteners. }\end{array}$ & 0 & 1 & 1 & 1 & 0 & 1 & 1 & 1 \\
\hline DS 14 & $\begin{array}{l}\text { Increase corrosion and dirt } \\
\text { resistance of parts. }\end{array}$ & 0 & 1 & 1 & 1 & 0 & 1 & 1 & 1 \\
\hline DS 15 & $\begin{array}{l}\text { Increase corrosion and dirt } \\
\text { resistance of surfaces. }\end{array}$ & 0 & 1 & 1 & 1 & 0 & 1 & 1 & 1 \\
\hline
\end{tabular}




\begin{tabular}{|c|c|c|c|c|c|c|c|c|c|}
\hline No & Attributes MLCP & $\begin{array}{l}\frac{3}{0} \\
\frac{0}{0} \\
\frac{0}{0} \\
\frac{0}{0} \\
\frac{0}{2} \\
\frac{2}{4}\end{array}$ & 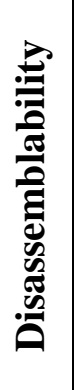 & 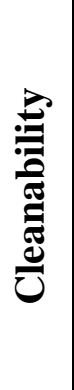 & 莺 & 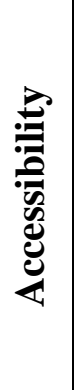 & 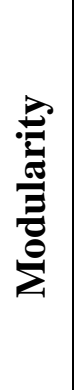 & 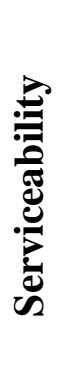 & 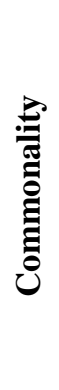 \\
\hline DS 16 & Increase modular design. & 1 & 1 & 0 & 0 & 0 & 1 & 1 & 0 \\
\hline DS 17 & $\begin{array}{l}\text { Increase standardisation and use of } \\
\text { common parts and materials. }\end{array}$ & 0 & 1 & 0 & 1 & 0 & 1 & 1 & 1 \\
\hline DS 18 & $\begin{array}{l}\text { Increase standardisation and use of } \\
\text { common fasteners. }\end{array}$ & 1 & 0 & 0 & 0 & 0 & 1 & 1 & 0 \\
\hline DS 19 & $\begin{array}{l}\text { Increase standardisation and use of } \\
\text { common connections. }\end{array}$ & 1 & 0 & 0 & 0 & 0 & 1 & 1 & 1 \\
\hline DS 20 & $\begin{array}{l}\text { Increase the usage of proven parts, } \\
\text { materials and preferred design. }\end{array}$ & 0 & 0 & 0 & 1 & 0 & 1 & 1 & 1 \\
\hline DS 21 & $\begin{array}{l}\text { Reduce part count by incorporating } \\
\text { multiple functions into single parts. }\end{array}$ & 0 & 0 & 1 & 0 & 0 & 0 & 1 & 0 \\
\hline DS 22 & Reduce disassembly time. & 0 & 0 & 0 & 0 & 0 & 0 & 0 & 0 \\
\hline DS 23 & Reduce assembly steps. & 1 & 0 & 0 & 0 & 0 & 1 & 0 & 0 \\
\hline DS 24 & $\begin{array}{l}\text { Reduce geometric features that trap } \\
\text { contaminants over the service life. }\end{array}$ & 0 & 0 & 1 & 1 & 0 & 0 & 1 & 0 \\
\hline DS 25 & $\begin{array}{l}\text { Reduce the number of cavities that } \\
\text { are capable of collecting residue } \\
\text { during cleaning operations. }\end{array}$ & 0 & 0 & 1 & 0 & 0 & 0 & 1 & 0 \\
\hline DS 26 & $\begin{array}{l}\text { Avoid the use of regulated and } \\
\text { restricted materials. }\end{array}$ & 0 & 0 & 0 & 0 & 0 & 0 & 0 & 0 \\
\hline DS 27 & $\begin{array}{l}\text { Avoid product or part features that } \\
\text { can be damaged during disassembly } \\
\text { processes. }\end{array}$ & 0 & 1 & 0 & 1 & 1 & 0 & 1 & 0 \\
\hline DS 28 & $\begin{array}{l}\text { Avoid product or part features that } \\
\text { can be damaged during cleaning } \\
\text { processes. }\end{array}$ & 0 & 0 & 1 & 1 & 0 & 0 & 1 & 0 \\
\hline
\end{tabular}

Refering to the AHP hierarchy structure of DFMLC, DFMLC model could generate one $4 \times 4$ matrix as the design criteria pairwise comparison for Level 2, four $3 \times 3$ matrices as DFX pairwise comparison with respect to four design criteria for Level 3, and three $8 \times 8$ matrices as design elements pairwise comparison with respect to three DFXs for Level 4. All pairwise comparison matrices for each of the AHP levels have been constructed using Equations 1-3. The consistency ratio (CR\%) achieved by these matrices must less than $10 \%$, indicating that the case study was under a good and acceptable condition (Brunelli, 2015). After consistency for the three matrices was determined with a CR value of less than $10 \%$ to ensure four matrices 
were in good condition (Brunelli, 2015), the overall priority vector for the design elements with respect of three DFXs was developed as shown in Figure 3. Also, the disassemblability achieved the first priority order of the design element at level 4.

From the modified AHP, The overall priority vector for DFXs which is level 3 can then be determined by multiplying the matrix with the priority vector of design criteria from level 2 . The calculation for the determination of level 3 is shown below:

$$
\left[\begin{array}{llll}
0.1721 & 0.1144 & 0.7074 & 0.1564 \\
0.7258 & 0.7857 & 0.1700 & 0.7450 \\
0.1020 & 0.0999 & 0.1226 & 0.0986
\end{array}\right] *\left[\begin{array}{l}
0.6474 \\
0.1149 \\
0.1272 \\
0.1106
\end{array}\right]=\left[\begin{array}{l}
0.2318 \\
0.6642 \\
0.1040
\end{array}\right]
$$

From the modified AHP, there is a matrix formed by three priority vectors of design elements concerning the three DFXs. The overall priority vector for design elements which is level 4 can then be determined by multiplying the matrix with the priority vector of DFXs from level 3. The calculation for the determination of level 4 is shown below:

$\left[\begin{array}{lll}0.1194 & 0.1229 & 0.1198 \\ 0.1937 & 0.2288 & 0.2197 \\ 0.1041 & 0.0869 & 0.1044 \\ 0.1420 & 0.1293 & 0.1242 \\ 0.0989 & 0.0948 & 0.0957 \\ 0.0856 & 0.0584 & 0.0992 \\ 0.2113 & 0.2068 & 0.1915 \\ 0.0451 & 0.0720 & 0.0455\end{array}\right] *\left[\begin{array}{l}0.2318 \\ 0.6642 \\ 0.1040\end{array}\right]=\left[\begin{array}{l}0.1218 \\ 0.2197 \\ 0.0927 \\ 0.1317 \\ 0.0959 \\ 0.0690 \\ 0.2062 \\ 0.0630\end{array}\right]$

Then, Figure 3 represents the priority order of the design elements based on the assumption of design strategy for the remanufacturable automotive component. Therefore, the importance ranking of the design elements for the case study on the remanufacturable engine based on the interviews. The design assumptions of the design strategy for automotive engines were arranged via interviews with remanufacturing specialists. The product structure $(64.74 \%)$, the design for configuration $(66.42 \%)$ and the disassemblability of the product $(21.97 \%)$ have achieved the first priority order of the design criteria at level 2, DFX at level 3 and the design elements at level 4 respectively in the modified AHP. Therefore, all MLCP design attributes need to be considered in designing a re-manufacturable engine. Both disassemblability and serviceability should also be emphasised in the design process as these two elements can ensure that an automotive engine is designed to be ready for remanufacturing. 
Disassemblability is one of the aspects of product development that focuses on resource recovery at the end of the product life-cycle (Joshi \& Gupta, 2017). Without disassemblability, almost all of the EOL options such as reuse, recycling, remanufacturing and disposal cannot be undertaken (Joshi \& Gupta, 2017). Indeed, this is because the disassembly process is the first step in all recovery processes to obtain the valuable components of the EOL product without causing any damage. If the component cannot be uninstalled, the process of cleaning, quality checking and maintenance cannot proceed. Therefore, the DFD concept needs to be considered in the design process to reduce the negative impact and costs associated with the remanufacturing process (Germani et al, 2014).

Also, serviceability is the second most important design element. Routine maintenance can maintain the quality of the product or component to extend its life-cycle (Matsumoto et al, 2016). The efficiency of serviceability depends on the design considerations for assemblability and disassemblability (Sassanelli et al, 2016). One of the aims of design for serviceability is to minimise the cost and time required for assembly and disassembly processes (Sassanelli et al, 2016). Also, the assemblability involved with re-installation should consider the reuse, remanufacturing and maintenance repairs. The three elements of this design are closely related to the properties of "ease of access" and "ease of handling" such remanufacturing properties as proposed by Sundin (2004).

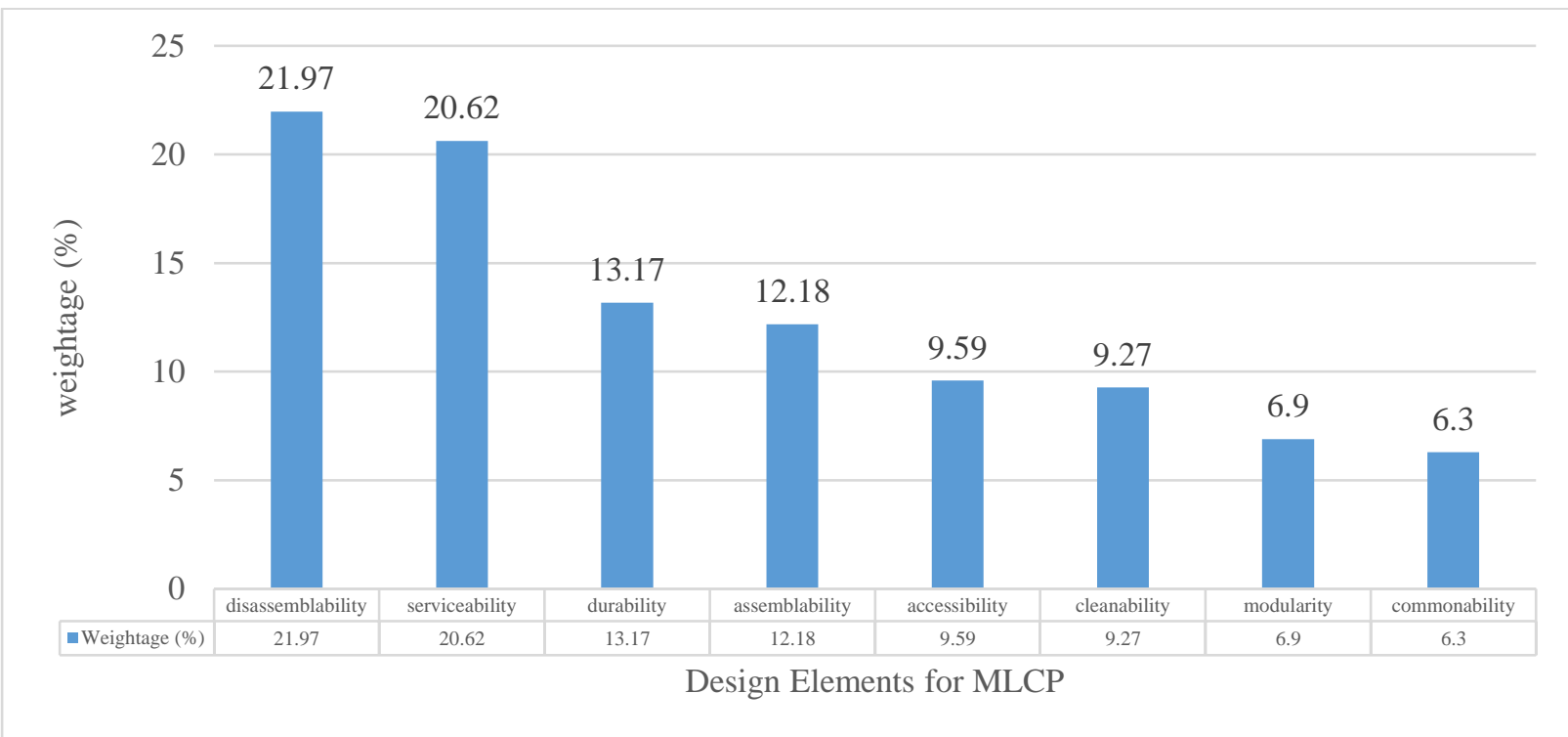

Figure 3. Importance ranking of design elements for the case study on the remanufacturable engine based on interviews. 
Disassemblability and serviceability should be emphasised in the design process as these two elements can help to ensure that an automotive engine is designed and ready for remanufacturing. However, other MLCP design elements such as cleanability, durability, accessibility, modularity and commonability still need to be taken into account in DFMLC. Accessibility is important as it simplifies the disassembly process (Vongbunyong \& Chen, 2015) and assembly process (Dunmade, 2013) as well as serviceability (Dunmade, 2013). Modularity is also important as it facilitates upgradability (Yang et al., 2015) while durability leads to hard-wearing and robust components to be reused several times (Dunmade, 2013). Cleanability is still one of the most important design elements in the design for remanufacturing to facilitate the cleaning process and minimise the associated costs (Kurilova-Palisaitiene \& Surdin, 2015). Thus, design strategies proposed via interviews can be referred to when designing an automotive engine as an MLCP.

AHP aims at quantifying relative priorities for a given set of attributes on a ratio scale based on the judgment of the decision-maker. Moreover, it stresses the importance of the intuitive judgments of a decision-maker and consistency of the comparison of alternatives in the decision-making process (Guan et al, 2009). The decision maker needs to compare the importance of two attributes simultaneously. The decision makers assign then weight ratios to indicate the strength of their preferences by using integers from 1 to 9 , which in principle could consist of the evaluation scale, with any numbers of the AHP (Koczkodaj et al, 2016). In this study, the design guidelines mapping matrices were used for pairwise comparison for all attributes, in order to clarify the judgment of the decision-maker as they became more quantitative. However, the conventional AHP has been found with several inherent weakness as described below:

i. Decision-makers may consider the importance of attributes in the form of weightage and face the difficulty of defining the appropriate scale in AHP pairwise comparison matrices;

ii. The opinion of more decision-makers needs to be collected in order to reduce any inconsistency. Hence an extended time is required in the design process;

iii. The mean value from the decision-makers may be a decimal point number which is against the common importance scale (1-9), which is in the form of a whole number; and 
iv. Decision-makers may have difficulty in assessing the importance scale for pairwise comparison due to a limited understanding of every attribute. Hence an effective AHP pairwise comparison matrix cannot be developed.

Therefore, the modified AHP model in this paper proposes a new method of estimating the importance scale in the pairwise comparison matrix. Accordingly, it is more quantitative and provides the following benefits:

i. Introduces a straightforward approach to evaluate the importance scale of pairwise comparisons for AHP.

ii. Enables product designers to ensure that their design considers MLCP through mapping their design strategies with necessary attributes.

iii. Provides a platform to study designing MLCP.

iv. Enables the complex decision-making process to be more rational and efficient.

v. The inconsistency of the pairwise comparison matrix can be checked without gathering several expert opinions.

\section{Conclusion}

This paper has discussed the development of a modified AHP as a new innovative method for generating AHP pairwise comparison matrices for the development of MLCP. The guideline mapping matrix against the MLCP design attributes presented in this study will further assist designers to consider MLCP requirements in their designs. Additionally, the mapping matrix of design strategies against the MLCP design attributes can check the design strategies generated as to whether the product is ready for MLC. Through the mapping matrices and equations for determining the importance scale of the MLCP, design attributes in the AHP were developed. Thus, the modified AHP provides a platform to study design ideas for MLCP generation. Based on the results of the case study, disassemblability and serviceability should be emphasised in the design process as the two elements can ensure that an automotive engine is designed and ready for remanufacturing. However, other MLCP design elements such as assemblability, cleanability, durability, accessibility, modularity and commonability still need to be considered in DFMLC. 


\section{Acknowledgement}

The authors would like to extend their greatest appreciation to The Ministry of Education, Malaysia for sponsoring this research under the FRGS grant - FRGS/2/2013/ TK01/ UKM/ $01 / 1$.

\section{References}

Abdullah, T., Wahab, D. \& Lashlem, A. (2013). An overview use of analytic hierarchy process (AHP) in design for remanufacturing activities. Proceedings of the International Symposium on the Analytic Hierarchy Process, 1-14.

Alamerew, Y.A. \& Brissaud, D. (2017). Evaluation of remanufacturing for product recovery: Multi-criteria decision tool for end-of-life selection strategy. 3rd International Conference on Remanufacturing.

Aziz, N.A., Wahab, D.A. \& Ramli, R. (2017). Establishment of engineering metrics for upgradable design of brake caliper. In. Campana, G., Howlett, R.J., Setchi, R. \& Cimtti, B. Sustainable Design and Manufacturing (ed.) 68, Italy: Springer Science and Business Media Deutschland GmbH, 87-97.

Brunelli, M. (2015). Priority vektor and consistency. In Introduction to the Analytic Hierarchy Process. SpringerBriefs in Operations Research, 17-27.

Cheung, W.M., Marsh, R., Griffin, P.W., Newnes, L.B., Mileham, A.R. \& Lanham, J,D. (2015). Towards cleaner production: A roadmap for predicting product end-of-life costs at early design concept. Journal of Cleaner Production, 87, 431-441.

Dunmade, I. (2013). Design for multi-lifecycle: A sustainability design concept. International Journal of Engineering Research and Applications, 3(2), 1413-1418.

Favi, C., Germani, M. \& Mandolini, M. (2016). Design for Manufacturing and Assembly vs. Design to Cost: Toward a multi-objective approach for decision-making strategies during conceptual design of complex products. Procedia CIRP, 50, 275-280.

Joshi, A.D. \& Gupta, S.M. (2017). Evaluation of design alternatives of end-of-life products under stochastic yields in multiple periods. American Journal of Computer Science and Information Engineering, 4(5), 52-64.

Germani, M., Mandolini, M., Marconi, M. \& Rossi, M. (2014). An approach to analytically evaluate the product disassemblability during the design process. Procedia CIRP, 21, 336341.

Go, T.F., Wahab, D.A. \& Hishamuddin, H. (2015). Multiple generation life-cycles for product sustainability: The way forward. Journal of Cleaner Production, 95, 16-29.

Guan, X., Wang, Y. \& Tao, L. (2009). Machining scheme selection of digital manufacturing based on genetic algorithm and AHP. Journal of Intelligent Manufacturing, 20(6), 661-669.

Gupta, S., Dangayach, G.S., Singh, A.K. \& Rao, P.N. (2015). Analytic hierarchy process (AHP) model for evaluating sustainable manufacturing practices in Indian electrical panel industries. Procedia - Social and Behavioural Sciences, 189, 208-216.

Koczkodaj, W.W., Mikhailov, L., Redlarski, G., Soltys, M., Szybowski, J., Tamazian, G., Wajch, E. \& Yuen, K.K.F. (2016). Important facts and observations about pairwise comparison. Fundamenta Informaticae, 144(3-4), 291-307. 
Kurilova-Palisaitiene, J., Lindkvist, L. \& Sundin, E. (2015). Towards facilitating circular product life-cycle information flow via remanufacturing. Procedia CIRP, 29, 780-785.

Kurilova-Palisaitiene, J. \& Sundin, E. (2015). Toward pull remanufacturing: A case study on material and information flow uncertainties at a German engine remanufacturer. Procedia CIRP, 26, 270-275.

Liu, H.C., You, J.X., Shan, M.M. \& Shao, L.N. (2015). Failure mode and effects analysis using intuitionistic fuzzy hybrid TOPSIS approach. Soft Computing, 19(4), 1085-1098.

Mai, 2014. Malaysia Automotive Roadmap 2014 - Highlight. Retrieved from http://muvata.org.my/uploads/3/1/7/5/31759905/a9rb701.pdf

Mastura, M.T., Sapuan, S.M. \& Mansor, M.R. (2015). A framework for prioritizing customer requirements in product design: Incorporation of FAHP with AHP. Journal of Mechanical Engineering and Sciences, 9, 1655-1670.

Matsumoto, M., Yang, S., Martinsen, K. \& Kainuma, Y. (2016). Trends and research challenges in remanufacturing. International Journal of Precision Engineering and Manufacturing - Green Technology, 3(1), 129-142.

Miti, 2020. National Automotive Policy 2020. Retried from https://www.miti.gov.my/index.php/pages/view/nap2020

Nahm, Y.E., Ishikawa, H. \& Inoue, M. (2013). New rating methods to prioritize customer requirements in QFD with incomplete customer preferences. International Journal of Advanced Manufacturing Technology, 65, 1587-1604.

Priyono, A., Ijomah, W.L. \& Bititci, U.S. (2015). Strategic operations framework for disassembly in remanufacturing. Journal of Remanufacturing, 5(11).

Sassanelli, C., Pezzotta, G., Pirola, F., Terzi, S. \& Rossi, M. (2016). Design for product service supportability (DfPSS) approach: A State of the art to foster product service system (PSS) design. Procedia CIRP, 47, 192-197.

Seperamaniam, T., Jalil, N.A.A. \& Zulkefli, Z.A. (2017). Hydrostatic bearing design selection for automotive application using pugh controlled convergence method. Procedia Engineering, 170, 422-429.

Sundin, E. (2004). Product and Process Design for Successful Remanufacturing. Doctoral thesis, Department of Management and Engineering, Assembly technology. Sweden: Linköpings Universitet.

Vongbunyong, S. \& Chen, W.H. (2015). Disassembly Automation, Sustainable Production, Life Engineering and Management. Switzerland: Springer.

Wadhwa, S., Madaan, J. \& Chan, F.T.S. (2009). Flexible decision modeling of reverse logistics system: A value adding MCDM approach for alternative selection. Robotics and ComputerIntegrated Manufacturing, 25(2), 460-469.

Yang, S.S., Ngiam, H.Y., Ong, S.K. \& Nee, A.Y.C. (2015). The impact of automotive product remanufacturing on environmental performance. Procedia CIRP, 29, 774-779.

Yüksel, H. (2010). Design of automobile engines for remanufacture with quality function deployment. International Journal of Sustainable Engineering, 3(3), 170-180.

Zha, X.F., Sriram, R.D. \& Lu, W.F. (2004). Evaluation and selection in product design for mass customization: A knowledge decision support approach. Artificial Intelligence for Engineering Design, Analysis and Manufacturing, 18, 87-109. 